\title{
Perioperative treatment of soft-tissue sarcoma
}

\author{
Christian Rothermundt (iD
}

Received: 3 November 2019 / Accepted: 29 November 2019 / Published online: 7 January 2020

(C) The Author(s) 2020

\begin{abstract}
Summary The standard treatment of high-risk localized extremity and trunk soft-tissue sarcoma is wide local excision and radiation therapy, which can be delivered pre- or postoperatively. Improved care for sarcoma patients at expert centres with multidisciplinary tumour boards, specialized pathologists, surgeons, radio-oncologists, and medical oncologists, according to national or international guidelines, has improved outcomes. Yet, a substantial number of patients will experience disease recurrence with metastatic spread and ultimately die from their disease. In many solid tumours neo/adjuvant chemotherapy has become an accepted standard treatment, whereas in softtissue sarcoma discussions on the use of cytotoxic therapy in localized and resectable disease are ongoing. Some centres demonstrated the feasibility and now treat with concomitant neoadjuvant chemoradiotherapy as standard. Others argue that treatments should be given in the order of the accompanying evidence (surgery $\rightarrow$ radiotherapy $\rightarrow$ chemotherapy), which does not take biology of the disease into account and probably attempts to simplify complex decision making processes. It is important to enhance our ability to identify patients at highest risk of recurrence, and to generate data and develop tools to predict which patients will benefit from neo/adjuvant systemic therapy most.
\end{abstract}

Keywords High-risk · Neodadjuvant · Adjuvant . Chemotherapy $\cdot$ Radiotherapy $\cdot$ Hyperthermia

\footnotetext{
C. Rothermundt ( $\square)$

Division of Oncology and Haematology, Kantonsspital

St. Gallen, Rorschacherstrasse 95, 9007 St. Gallen,

Switzerland

christian.rothermundt@kssg.ch
}

In solid tumours there is good evidence for the application of neo/adjuvant systemic therapy as a means to reduce the risk of local relapse and distant disease recurrence, with the objective to improve relapse-free and overall survival (OS), e.g. in non-small cell lung cancer [1, 2], colon cancer [3], rectal cancer [4, 5], breast cancer [6], melanoma [7, 8], and bladder cancer [9-11]. This data has been widely adopted in the oncologic community. In breast cancer, guidance for the use of adjuvant chemotherapy is now provided by a gene recurrence score, supplementing clinicalrisk stratification and thereby better selecting patients likely to benefit [12].

While patients with bone sarcomas (e.g. osteosarcoma and Ewing sarcoma), rhabdomyosarcomas and other typical soft tissue sarcomas (STS) among children and adolescents are usually treated according to multimodal regimens, in which systemic chemotherapy is an important component, the role of neo/ adjuvant chemotherapy for localized STS remains debated.

Surgical resection and pre- or postoperative radiotherapy attain a high local control rate and are unopposed elements in the effort to cure STS [13-15]. About $50 \%$ of patients with high-risk (high-grade, large and deep) STS will be treated successfully using these local modalities. Yet, the risk of distant recurrence remains high and a substantial number of patients succumb to advanced STS [16]. This elucidates the medical need to improve treatment strategies and ultimately outcome in STS. It is important to identify which patients are at risk for recurrence and effective strategies to prevent such recurrences [17]. 
Why neo/adjuvant chemotherapy is not a standard in high-risk localized STS

The European Society of Medical Oncology guidelines state the following: There is no consensus on the current role of adjuvant chemotherapy. Study results are conflicting, in the presence of negative results from the largest studies, though data are available from smaller studies suggesting that it might improve, or at least delay, distant and local recurrence in highrisk patients [18].

Due to the rarity [19] and the biologic heterogeneity [20] of STS good quality clinical trials have been difficult to perform. Until now only one randomized study was published comparing neoadjuvant chemotherapy followed by surgical resection versus primary surgery [21]. In 150 patients with high-risk STS no advantage for the application of three cycles of doxorubicin $\left(50 \mathrm{mg} / \mathrm{m}^{2}\right)$ and ifosfamide $\left(5 \mathrm{~g} / \mathrm{m}^{2}\right)$ was demonstrated in terms of relapse-free survival and OS. This trial was underpowered and used inappropriate low drug doses and therefore no definite conclusions can be drawn.

In a meta-analysis of 14 randomized studies on adjuvant chemotherapy, published in 1997, a statistically significant improvement in the time to local and distant recurrence and overall recurrence-free survival was reported. There was a trend towards improved OS [22]. Anthracycline-based adjuvant chemotherapy provided an absolute survival benefit of $4 \%$ (range $1-9 \%)$ at 10 years; however this was not significant. The clearest evidence of a treatment effect on survival (7\%) could be demonstrated for patients with extremity STS. Criticism of the studies comprised: use of marginally active drugs, variable doses of anthracyclines and ifosfamide, no restriction to high-risk STS and even enrolment of patients with gastrointestinal stroma tumours [23].

In the Italian cooperative trial 104 patients with high-risk extremity or trunk STS were randomized to resection followed by five cycles of adjuvant epirubicin $\left(60 \mathrm{mg} / \mathrm{m}^{2}\right)$ and ifosfamide $\left(9 \mathrm{~g} / \mathrm{m}^{2}\right)$ versus surgery alone. A per protocol interim analysis of disease-free survival (DFS) had been planned after enrolment of half the patients: this analysis revealed a significant difference in favour of chemotherapy and the study was closed prematurely and published [24]. Unfortunately, with longer follow-up, the effect of adjuvant chemotherapy could not be sustained [25].

A retrospective analysis of non-randomized data prospectively included in the French Sarcoma Group database between 1980 and 1999 alluded to an advantage of adjuvant chemotherapy. In all, 262 patients with grade 3 STS had received adjuvant chemotherapy and 363 not. In these grade 3 STS patients, adjuvant chemotherapy was associated with a significant benefit in terms of metastasis-free survival (hazard ratio [HR] 0.7 [95\% CI 0.6-0.9], $p=0.01$ ) and an absolute risk reduction of metastatic relapse of 9\% (5-year metastasis-free survival: $58 \%$ versus $49 \%$ ). Adjuvant chemotherapy demonstrated a significant benefit in terms of OS (HR 0.6 [95\% CI 0.5-0.8], $p=0.0002$ ) and an absolute risk reduction of death of $13 \%$ (5-year OS: $58 \%$ versus $45 \%$ ) [26].

In contrast, a European Organisation for Research and Treatment of Cancer (EORTC) Soft Tissue and Bone Sarcoma Group (STBSG) study (EORTCSTBSG 62931) did not show a benefit for patients who were randomized to five cycles of adjuvant doxorubicin $\left(75 \mathrm{mg} / \mathrm{m}^{2}\right)$ and ifosfamide $\left(5 \mathrm{~g} / \mathrm{m}^{2}\right)$ [27]. However, less than $50 \%$ of patients had grade 3 STS (6\% grade 1 and $48 \%$ grade 2 ) and $12 \%$ of patients were treated for local recurrences, hence not in a real adjuvant setting.

\section{Why neo/adjuvant chemotherapy should be a standard in high-risk localized STS}

Despite the fact that no level 1A evidence had been provided for neither neo- nor adjuvant chemotherapy, the Italian and Spanish Sarcoma groups performed a randomized phase- 3 trial in high-risk STS and demonstrated non-inferiority of 3 cycles of neoadjuvant chemotherapy compared to 5 cycles chemotherapy, split in 3 pre- and 2 postoperative courses of epirubicin $\left(120 \mathrm{mg} / \mathrm{m}^{2}\right)$ and ifosfamide $\left(9 \mathrm{~g} / \mathrm{m}^{2}\right)$. In this trial, the objective response rate was $25 \%$, but minor responses were observed in up to $41 \%$ of patients [28]. In addition, patients who responded to neoadjuvant chemotherapy had better early oncologic outcomes than those who did not, and this effect was sustained over a longer follow-up period [29].

Similarly, the trial to assess the safety and efficacy of regional hyperthermia with pre- and postoperative chemotherapy for high-risk STS (EORTC 62961ESHO 95) did not provide a chemotherapy-free comparator. The study showed superiority for the addition of hyperthermia in terms of DFS (HR 0.70 [95\% CI 0.54-0.92], $p=0.011$ ) compared with polychemotherapy (etoposide $500 \mathrm{mg} / \mathrm{m}^{2}$, ifosfamide $6 \mathrm{~g} / \mathrm{m}^{2}$ and doxorubicin $50 \mathrm{mg} / \mathrm{m}^{2}$ ) alone [30]. Patients randomized to chemotherapy plus hyperthermia had prolonged survival rates compared with those randomized to neoadjuvant chemotherapy alone (HR 0.73 [95\% CI 0.54-0.98], $p=0.04$ ) [31].

More recently, ISG-STS 1001 enrolled high-risk extremity and trunk STS patients in Italy, Spain, France and Poland. Patients were either treated in the standard arm with three cycles of epirubicin $\left(60 \mathrm{mg} / \mathrm{m}^{2}\right)$ and ifosfamide $\left(9 \mathrm{~g} / \mathrm{m}^{2}\right)$ or in the experimental arm with a histotype-tailored regimen: patients with high-grade myxoid liposarcoma received trabectedin $\left(1.3 \mathrm{mg} / \mathrm{m}^{2}\right.$ via $24 \mathrm{~h}$ continuous infusion); patients with leiomyosarcoma gemcitabine $\left(1800 \mathrm{mg} / \mathrm{m}^{2}\right)$ and dacarbazine $\left(500 \mathrm{mg} / \mathrm{m}^{2}\right)$; patient with synovial sarcoma high-dose ifosfamide $\left(14 \mathrm{~g} / \mathrm{m}^{2}\right.$ in 14 days via continuous infusion); patients with malignant peripheral nerve sheath tumour received etoposide $\left(450 \mathrm{mg} / \mathrm{m}^{2}\right)$ and ifosfamide $\left(9 \mathrm{~g} / \mathrm{m}^{2}\right)$; and 


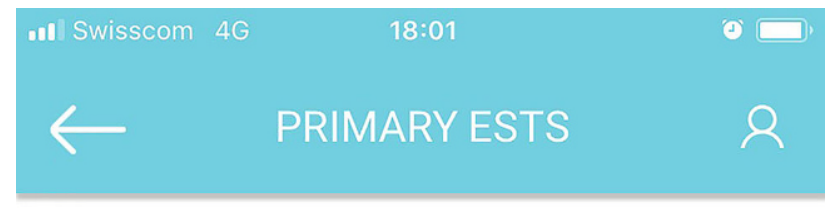

AGE (18-100)

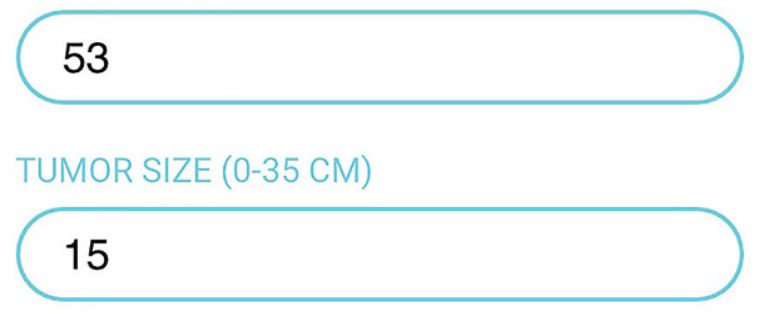

GRADE

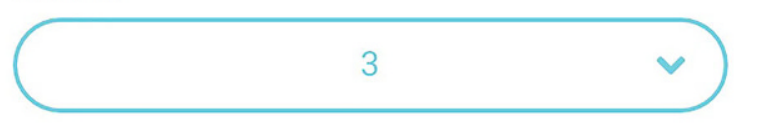

HISTOLOGY

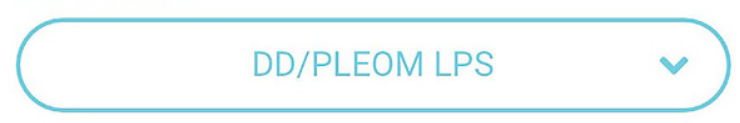

Calculate

Fig. 1 SARCULATOR with patient- and tumour-related characteristics.

patients with undifferentiated pleomorphic sarcomas received gemcitabine $\left(900 \mathrm{mg} / \mathrm{m}^{2}\right.$ day 1 and 8$)$, and docetaxel $\left(75 \mathrm{mg} / \mathrm{m}^{2}\right.$ day 8) [32]. The histotype-tailored approach has gained momentum in the medical treatment of advanced STS in the past few years as a possible way to overcome resistance. In a futility analysis after a short follow-up of 12.2 months the projected DFS at 46 months was $62 \%$ [95\% CI 48-77] in the standard chemotherapy group and $38 \%(22-55)$ in the histotype-tailored chemotherapy group (HR 2.0 [95\% CI 1.22-3.26], $p=0.006$ ). No benefit of a neoadjuvant histotype-tailored chemotherapy regimen over the standard chemotherapy regimen could be demonstrated. However, the authors postulated that the benefit seen with the standard chemotherapy regimen suggests that this benefit might be the added value of neoadjuvant chemotherapy itself in patients with high-risk STS: the study results indicate that the

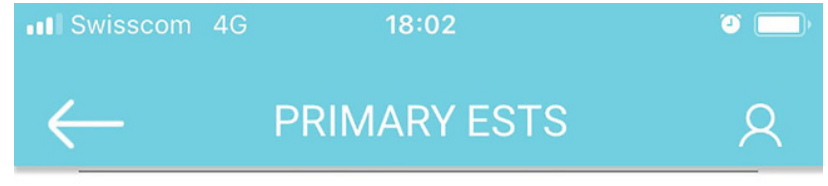

5-year OS

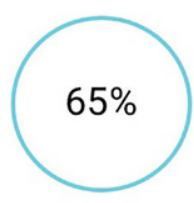

info

\section{0-year OS}

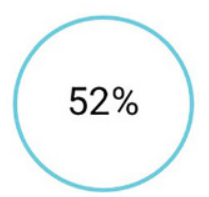

info

\section{5-year DM}

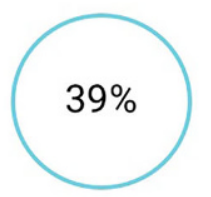

info

\section{0-year DM}

Fig. 2 SARCULATOR estimate of oncological outcomes in terms of overall survival (OS) and incidence of distant metastasis (DM), which guided the recommendation for neoadjuvant chemotherapy.

difference seen in DFS and OS is the consequence of a real effect of standard chemotherapy in high-risk STS.

SARCULATOR is a newly developed and validated prognostic nomogram, and can be downloaded as an app [33]. SARCULATOR helps to assess the individual risk of STS patients with extremity and retroperitoneal sarcomas and is a useful tool in the decision-making process [34]. In a retrospective analysis of EORTCSTBSG 62931, 10-year predicted probability of OS (prOS) was calculated using SARCULATOR. In patients with pr-OS $<60 \%$ a significant DFS (HR 0.49 [95\% CI $0.28-0.85$ ]) and OS (HR 0.50 [95\% CI 0.30-0.90]) benefit was detected with adjuvant chemotherapy (Figs. 1 and 2; [35]). Primary extremity STS patients treated within three European and one North American reference centres in a 20-year time span were included in a retrospective analysis across major histological sub- 
types. They reported a trend towards a 5\% survival benefit associated with neo/adjuvant chemotherapy administration and this is consistent with the published literature [36]. We performed a survey among EORTC STBSG members in 2017: Experts from 12 centres and seven countries were polled regarding their criteria used for decision-making and their use of preand postoperative chemotherapy. Substantial heterogeneity in practice patterns was revealed and no recommendations could be provided for general use [37].

However, there are compelling arguments for the use of neoadjuvant chemotherapy in STS:

- Induction of tumour regression and facilitation of limb- or organ-sparing surgery;

- Early administration of chemotherapy to accelerate treatment of micrometastatic disease;

- Better tolerability of systemic chemotherapy before resection and radiotherapy;

- Identification of patients with chemotherapy-sensitive tumours;

- Selection of patients who do not develop metastatic disease while receiving preoperative chemotherapy, as those are unlikely to benefit from an aggressive, potentially morbid surgery [17].

The French Sarcoma Group is currently performing a randomized clinical trial to assess the use of a gene expression signature (CINSARC) [38] to guide intensity of adjuvant chemotherapy in high-risk STS and the EORTC is planning a study to evaluate neoadjuvant chemotherapy in retroperitoneal lipo- and leiomyosarcomas (STRASS2).

While more evidence to support the use of neo/ adjuvant chemotherapy in high-risk STS is awaited from clinical trials and registries, systemic chemotherapy should be considered at the multidisciplinary tumour board and discussed with the patients on a routine basis. Obviously, more refined selection of patients and therapies is key to improve outcome and spare unnecessary toxicity. In the future, novel agents (e.g. immunotherapy) may change our treatment strategies [39].

Funding Research funding was received from Astellas Pharma.

Conflict of interest C. Rothermundt: Consulting or Advisory Role: Novartis, Pfizer, Astellas Pharma, Eisai, PharmaMar, Bristol-Myers Squibb, MSD Oncology.

Open Access This article is licensed under a Creative Commons Attribution 4.0 International License, which permits use, sharing, adaptation, distribution and reproduction in any medium or format, as long as you give appropriate credit to the original author(s) and the source, provide a link to the Creative Commons licence, and indicate if changes were made. The images or other third party material in this article are included in the article's Creative Commons licence, unless indicated otherwise in a credit line to the material. If material is not included in the article's Creative Commons licence and your intended use is not permitted by statutory regulation or exceeds the permitted use, you will need to obtain permission directly from the copyright holder. To view a copy of this licence, visit http:// creativecommons.org/ licenses/by/4.0/.

\section{References}

1. Douillard JY, Rosell R, De Lena M, et al. Adjuvant vinorelbine plus cisplatin versus observation in patients with completely resected stage ib-iiia non-small-cell lung cancer (adjuvant navelbine international trialist association [anita]): A randomised controlled trial. Lancet Oncol. 2006;7:719-27.

2. Curioni-Fontecedro A, Perentes JY, Gelpke H, et al. Preoperative chemotherapy and radiotherapy concomitant to cetuximab in resectable stage iiib nsclc: A multicentre phase 2 trial (sakk 16/08). Br JCancer. 2019;120:968-74.

3. Andre T, Boni C, Mounedji-Boudiaf L, et al. Oxaliplatin, fluorouracil, and leucovorin as adjuvant treatment for colon cancer. NEngl J Med. 2004;350:2343-51.

4. Bosset JF, Collette L, Calais G, et al. Chemotherapy with preoperative radiotherapy in rectal cancer. N Engl J Med. 2006;355:1114-23.

5. Hofheinz RD, Wenz F, Post S, et al. Chemoradiotherapy with capecitabine versus fluorouracil for locally advanced rectal cancer: a randomised, multicentre, non-inferiority, phase 3 trial. Lancet Oncol. 2012;13:579-88.

6. von Minckwitz G, Procter M, de Azambuja E, et al. Adjuvant pertuzumab and trastuzumab in early her2-positive breast cancer. NEngl J Med. 2017;377:122-31.

7. Eggermont AM, Chiarion-Sileni V, Grob JJ, et al. Prolonged survival in stage iii melanoma with ipilimumab adjuvant therapy. NEngl J Med. 2016;375:1845-55.

8. Weber J, Mandala M, Del Vecchio M, et al. Adjuvant nivolumab versus ipilimumab in resected stage iii or iv melanoma. NEngl J Med. 2017;377:1824-35.

9. Grossman HB, Natale RB, Tangen CM, et al. Neoadjuvant chemotherapy plus cystectomy compared with cystectomy alone for locally advanced bladder cancer. N Engl J Med. 2003;349:859-66.

10. Plimack ER, Hoffman-Censits JH, Viterbo R, et al. Accelerated methotrexate, vinblastine, doxorubicin, and cisplatin is safe, effective, and efficient neoadjuvant treatment for muscle-invasive bladder cancer: Results of a multicenter phase ii study with molecular correlates of response and toxicity. JClin Oncol. 2014;32:1895-901.

11. PeytonCC, TangD, ReichRR, etal. Downstagingand survival outcomes associated with neoadjuvant chemotherapy regimens among patients treated with cystectomy for muscleinvasive bladder cancer. JAMA Oncol. 2018;4:1535-42.

12. Sparano JA, Gray RJ, Ravdin PM, et al. Clinical and genomic risk to guide the use of adjuvant therapy for breast cancer. NEngl J Med. 2019;380:2395-405.

13. Eilber FC, Rosen G, Nelson SD, et al. High-grade extremity soft tissue sarcomas: factors predictive of local recurrence and its effect on morbidity and mortality. Ann Surg. 2003;237:218-26.

14. YangJC, ChangAE, BakerAR, etal. Randomized prospective study of the benefit of adjuvant radiation therapy in the treatment of soft tissue sarcomas of the extremity. J Clin Oncol. 1998;16:197-203.

15. Haas RL, Miah AB, LePechoux C, et al. Preoperative radiotherapy for extremity soft tissue sarcoma; past, present and future perspectives on dose fractionation regimens and combined modality strategies. Radiother Oncol. 2016;119:14-21.

16. Coindre JM, Terrier P, Guillou L, et al. Predictive value of grade for metastasis development in the main histologic types of adult soft tissue sarcomas: A study of 1240 patients 
from thefrench federation of cancer centers sarcomagroup. Cancer. 2001;91:1914-26.

17. Baldini EH, Le Cesne A, Trent JC. Neoadjuvant chemotherapy, concurrent chemoradiation, and adjuvant chemotherapy for high-risk extremity soft tissue sarcoma. Am Soc Clin OncolEduc Book. 2018;38:910-5.

18. Casali PG, Abecassis N, Bauer S, et al. Soft tissue and visceral sarcomas: Esmo-euracan clinical practice guidelines for diagnosis, treatment and follow-up. Ann Oncol. 2018;29:iv51:iv67.

19. Gatta G, van der Zwan JM, Casali PG, et al. Rare cancers are not so rare: The rare cancer burden in europe. Eur J Cancer. 2011;47:2493-511.

20. Who classification of tumours of soft tissue and bone. International Agency for Research on Cancer (IARC), 69372 Lyon Cedex 08, France, 2013:

21. Gortzak E, Azzarelli A, Buesa J, et al. A randomised phase ii study on neo-adjuvant chemotherapy for 'high-risk' adult soft-tissue sarcoma. Eur JCancer. 2001;37:1096-103.

22. Adjuvant chemotherapy for localised resectable softtissue sarcoma of adults: Meta-analysis of individual data. Sarcoma meta-analysis collaboration. Lancet 1997;350:1647-1654.

23. Hofer S, Reichardt P. Perioperative systemtherapie bei hochrisiko-weichteilsarkomen - bereits konsensfähig? JOnkol. 2019;5:32-4.

24. Frustaci S, Gherlinzoni F, De Paoli A, et al. Adjuvant chemotherapy for adult soft tissue sarcomas of the extremities and girdles: results of the italian randomized cooperative trial. JClin Oncol. 2001;19:1238-47.

25. Frustaci S, De Paoli A, Bidoli E, et al. Ifosfamide in the adjuvant therapy of soft tissue sarcomas. Oncology. 2003;65(Suppl2):80-4.

26. Italiano A, Delva F, Mathoulin-Pelissier S, et al. Effect of adjuvant chemotherapy on survival in fnclcc grade 3 soft tissue sarcomas: A multivariate analysis of the french sarcoma group database. Ann Oncol. 2010;21:2436-41.

27. Woll PJ, Reichardt P, Le Cesne A, et al. Adjuvant chemotherapy with doxorubicin, ifosfamide, and lenograstim for resected soft-tissue sarcoma (eortc 62931): a multicentre randomised controlled trial. Lancet Oncol. 2012;13:1045-54.

28. Gronchi A, Frustaci S, Mercuri M, et al. Short, full-dose adjuvant chemotherapy in high-risk adult soft tissue sarcomas: A randomized clinical trial from the italian sarcoma group and the spanish sarcoma group. J Clin Oncol. 2012;30:850-6.

29. Gronchi A, Stacchiotti S, Verderio P, et al. Short, fulldose adjuvant chemotherapy (ct) in high-risk adult soft tissue sarcomas (sts): Long-term follow-up of a randomized clinical trial from the italian sarcoma group and the spanish sarcoma group. Ann Oncol. 2016;27:2283-8.

30. Issels RD, Lindner LH, Verweij J, et al. Neo-adjuvant chemotherapy alone or with regional hyperthermia for localised high-risk soft-tissue sarcoma: A randomised phase 3 multicentre study. Lancet Oncol. 2010;11:561-70.
31. Issels RD, Lindner LH, Verweij J, et al. Effect of neoadjuvant chemotherapy plus regional hyperthermia on long-term outcomes among patients with localized high-risk soft tissue sarcoma: The eortc 62961-esho 95 randomized clinical trial. JAMA Oncol. 2018;4:483-92.

32. Gronchi A, Ferrari S, Quagliuolo V, et al. Histotype-tailored neoadjuvant chemotherapy versus standard chemotherapy in patients with high-risk soft-tissue sarcomas (isgsts 1001): An international, open-label, randomised, controlled, phase 3, multicentre trial. Lancet Oncol. 2017;18:812-22.

33. https://www.sarculator.com/

34. Callegaro D, Miceli R, Bonvalot S, et al. Development and external validation of two nomograms to predict overall survival and occurrence of distant metastases in adults after surgical resection of localised soft-tissue sarcomas of the extremities: A retrospective analysis. Lancet Oncol. 2016;17:671-80.

35. Pasquali S, Pizzamiglio S, Touati N, et al. The impact of chemotherapy on survival of patients with extremity and trunk wall soft tissue sarcoma: Revisiting the results of the eortc-stbsg 62931 randomised trial. Eur J Cancer. 2019;109:51-60.

36. Callegaro D, Miceli R, Bonvalot S, et al. Impact of perioperative chemotherapy and radiotherapy in patients with primary extremity soft tissue sarcoma: Retrospective analysis across major histological subtypes and major reference centres. EurJCancer. 2018;105:19-27.

37. Rothermundt C, Fischer GF, Bauer S, et al. Pre- and postoperative chemotherapy in localized extremity soft tissue sarcoma: A european organization for research and treatment of cancer expert survey. Oncologist. 2018;23:461-7.

38. Chibon F, Lagarde P, Salas S, et al. Validated prediction of clinical outcome in sarcomas and multiple types of cancer on the basis of a gene expression signature related to genome complexity. Nat Med. 2010;16:781-7.

39. Ng V, Sausville E, Miller K, et al. Neoadjuvant combination immunotherapy/radiation for high-risk soft tissue sarcoma (nexis): Preliminary results from an integrated phase i/ii, single-arm, prospective clinical trial. Presented at Musculoskeletal Tumor Society Annual Meeting; Portland. 2019.

Publisher's Note Springer Nature remains neutral with regard to jurisdictional claims in published maps and institutional affiliations.

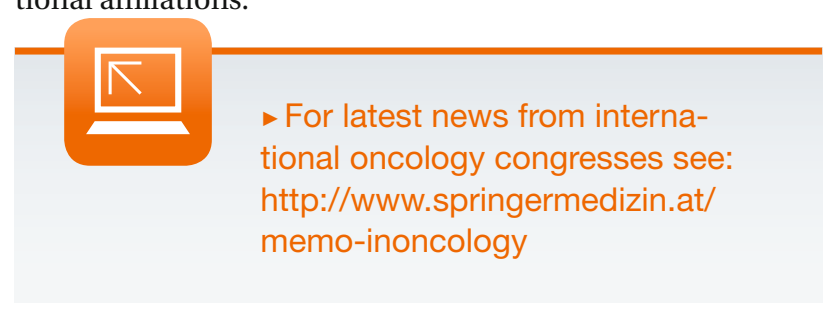

